\title{
Carbonate fine- grained concrete with enhanced internal energy dissipation properties
}

\author{
Vladimir Belov*, Pavel Kuliaev, and Temur Barkaya \\ Tver State Technical University, Civil Construction Department, 22, Af. Nikitin Quay, Tver, 170026, \\ Russia
}

\begin{abstract}
In this paper, research is carried out in the field of application of carbonate fine filler and hyper- and superplasticizers for enhancing microlevel energy dissipation in fine-grained concrete. The joint effect of a hyperand superplasticizing additive including limestone microfiller on the mechanical properties of fine-grained carbonate concrete has also been studied. The main parameter of concrete properties considered in this paper is stress intensity factor. It is determined in conducting incongruent tests of concrete samples-prisms for bending in accordance with the present standard.
\end{abstract}

\section{Experiment}

\subsection{Introduction}

In addition to internal forces, the action of loads is restricted by dissipative forces that cause energy dissipation in structures during loading. These forces are divided into external and internal. External dissipative forces include dynamic and collapse forces that occur when the base of the structure is deformed. Internal forces (friction) are caused by microplastic deformations of structural microparticles and friction in the joints [1]. The effect of these resistances on the structures is different and depends on many factors. Weak connections between internal joints due to dry friction intensively affect energy dissipation [2]. Under certain conditions, friction in the joints can dissipate energy several times greater than the internal friction in the construction material. But internal process of dissipation on the microcrack level must not be ignored. The energy dissipation due to internal friction and structural hysteresis occurs during gradual loading and is caused by microraptures and brittle dislocations appearing as small abrupt dynamic strains on microlevels [3]. These are inherent in concrete as an anisotropic and inhomogenius material. Therefore, these processes in individual structures are usually not taken into due account in simplified designing of structures on carbonate fine- grained concrete that reduce the design to a system with a single degree of freedom [4,5]. Considering these forces is especially important for structures

\footnotetext{
*Vladimir Belov: vladim-bel@yandex.ru
} 
consisting of many elements, since individual elements vary in microstrains before reaching the crucial displacement of the whole structure.

\subsection{Materials}

Three concrete compositions with three samples in each (Table 1) were compared for stress intensity factor. Two on a carbonate aggregate (with hyper- and superplasticizer) and one on a sand-gravel compound aggregate. Portlandcement CEM I 42.5 was used in the tests. Superplasticizer C-3 in the amount of 0.75 mass. \% of cement and hyperplasticizer melment F10 in the amount of 0.2 mass. \% of cement were used in compositions.

Specimens (short beams 400X100X100) were tested for bending.

Table 1. Sand-gravel and carbonate mixtures compositions, $\mathrm{kg}$ per $1 \mathrm{~m}^{3}$

\begin{tabular}{|c|c|c|c|}
\hline Component & Sand-gravel & Carbonate with C-3 & Carbonate with F10 \\
\hline Cement & 620 & 336 & 310 \\
\hline Sand-gravel compound & 1480 & - & - \\
\hline Limestone aggregate & - & 1528 & 280 \\
\hline Water & 286 & 310 & 0,35 \\
\hline W/C ratio & 0,44 & 0,35 & 362 \\
\hline Limestone filler & - & 336 & - \\
\hline SP-1 & - & 2,5 & 0,65 \\
\hline F10 & - & - & \\
\hline
\end{tabular}

\subsection{Technics}

The energy dissipation process in concrete involves mechanisms with various structural levels. According to the Standard it is determined through incongruent tests. Evaluation of the stress intensity factor is made by the standard test-in geometry formula.

Experimental device with a standard specimen is shown on fig. 1. A small incision is made on the stretched side of the beam in strict accordance with the Standard. Also, on the peak of possible crack to propagate an electrical gauge is glued to registrate the crack initiation.

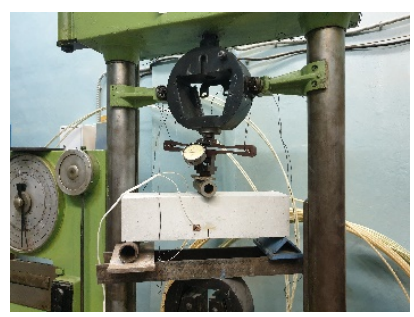

Fig. 1. Experimental device with a standard specimen. 


\section{Test results}

The following is test results indicating values of stress intensity factor grouped in table 2 .

Table 2. Stress intensity factor

\begin{tabular}{|c|c|c|c|}
\hline \multirow{2}{*}{$\begin{array}{c}\text { Concrete } \\
\text { compositions and } \\
\text { stress intensity factor }\end{array}$} & $\begin{array}{c}\text { Cand-gravel } \\
\text { compound }\end{array}$ & $\begin{array}{c}\text { Carbonate } \\
\text { concrete with C-3 }\end{array}$ & $\begin{array}{c}\text { Carbonate concrete } \\
\text { with F10 }\end{array}$ \\
\hline$K_{i}$ & 0,0042 & 0.0044 & 0.0045 \\
\hline
\end{tabular}

According to the table, the more limestone filler is in the paste the higher are the values of the stress intensity factor. Limestone filler with super- and hyperplasticizers create specific microplastic zones all around microcracks thereby reducing total brittleness of cement stone and depriving cracks the internal energy to propagate. Micro-cracks seems to be distributed evenly throughout the volume.

\section{Summary and prospects}

Limestone filler in complex additive with super- and hyperplasticizers reveals good internal energy dissipation features to fine-grained carbonate concrete. When a super- and hyperplasticizing component is added to the composition of fine-grained carbonate concrete, the internal energy dissipation increase, as compared to heavy fine-grained concrete on a sandgravel aggregate, showing lower dissipative capacity. To boot, a mixture with hyperplasticizer reveals greater values of stress intensity factor. All this suggests that the addition of super- and hyperplasticizing additives to the composition of fine-grained carbonate concrete in order to improve mechanical properties for the inner energy dissipation contributing to lower brittleness is appropriate. Limestone filler has good granular composition to ensure forming plastic micro-zones. This results in improved dissipation capacity of concrete, which is shown through greater values of stress intensity factor for specimens containing limestone and super- and hyperplasticizers. All this make limestone fine-grained concrete a composite with enhanced internal energy dissipation properties.

\section{References}

1. El Shamy U, Denissen C. Microscale energy dissipation mechanisms in cyclicallyloaded granular soils. Geotechnical and Geological Engineering; 30(2):343-361. (2012)

2. S. Y. Alam, A. Loukili.Transition from energy dissipative processes to displacement discontinuities during concrete failure. Ecole Centrale de Nantes, Nantes, France, 9th International Conference on Fracture Mechanics of Concrete and Concrete Structures, pp. 8 (2015)

3. Daria Scerrato, Ivan Giorgio, Alessandro Della Corte, Angela Madeo, Ali Limam. A micro-structural model for dissipation of phenomena in the concrete. Wiley, 39 (18), pp.2037-2052. 7. (2015)

4. P. Desnerck. Stress-strain behavior of self-compacting concretes containing limestone fillers. Ernst\&Sohn, Structural concrete 13, v.2, Berlin (2012)

5. Y. S Alam,., Kotronis P. and Loukili A.. Crack propagation and size effect in concrete using a non-local damage model. Engineering Fracture Mechanics 109, pp. 246-261. (2013) 